\title{
Methodology for economic assessment of energy-saving solutions in the reconstruction projects of residential buildings
}

\author{
Violetta Politi ${ }^{1, *}$ \\ ${ }^{1}$ Moscow State University of Civil Engineering, 26, Yaroslavskoye shosse, Moscow, 129337, Russia
}

\begin{abstract}
The paper investigates the issues of feasibility study of energysaving measures. It is proposed to revise the traditional approach to assessing the efficiency of capital investments in the projects of reconstruction of residential facilities, aimed at implementation of energysaving solutions. A special feature of an assessment of the efficiency of thermal modernization of buildings is the forecasting of future tariffs for energy carriers, the level of which directly depends on the macroeconomic situation both in the country and in the world, which makes the reliability of the estimate difficult. The author suggests using average forecasted tariff rates depending on the value of the discount rate, as well as the effect and payback period of costs not only for the investor, but also for the consumer of thermal energy, consisting in the amount of saving financial resources for the estimated operation period of thermal engineering measures.
\end{abstract}

\section{Introduction}

One of the key problems restraining the implementation of the state energy saving policy is the absence of a unified methodological approach to a comprehensive assessment of the economic efficiency of the use of energy-saving technologies. The absence of general approaches to a comprehensive assessment of the efficiency of the introduction of new energy efficient technologies, materials and equipment leads to the adoption of incorrect decisions on financing of energy-saving measures and, accordingly, to unjustified losses of funds and a decrease in the efficiency of resource use, including municipal and regional budgets [1].

The general methodologies for assessing the energy-saving measures are aimed at calculating the overall economic effect that the municipal and regional economies receive as a result of a reduction in capital investments in energy generation, and the assessment of the consumer effect remains uninvolved.

Therefore, this paper is dedicated to assessment of the two-way effect both for the investor and for the consumer (the homeowner). The proposed methodology for the economic assessment of capital investments in improving of the energy efficiency of existing buildings contains criteria that allow assessing the investment attractiveness and economic efficiency of thermal engineering measures [2].

\footnotetext{
*Corresponding author: polity_violca@list.ru
} 
Most of the scientific papers dedicated to the study of the issue of thermal modernization of buildings relied on an income method for assessing the efficiency of investments, which is based on the following dependence:

$$
I C(1+r)^{t}=S M+S M(1+r)+\cdots+S M(1+r)^{t-1}
$$

where IC - capital investments in the reconstruction associated with thermal protection measures, expressed in current prices; SM - annual savings of funds; $r$ - capitalization rate in absolute units; $\mathrm{t}$ - economic life of the reconstruction project, years.

The value of the indicator $t$, under which equation will be fulfilled, is called the payback period of capital investments. Based on the theory of the money value over time, this approach has become very popular due to the simplicity and clarity of mathematical operations. The disadvantage of this approach is that the assessment of the result of investing in energy-saving technologies will refer to the future period of time, and not to the current one [3].

\section{Materials and methods}

To increase the reliability of an assessment, it is preferable to use the income method with discounting of the received funds by the current period of time. For this purpose we perform a discounting operation of the equation (1) upon condition that the rate of capitalization and the discount rate are equal:

$$
\frac{I C(1+r)^{t}}{(1+r)^{t}}=\frac{S M}{1+r}+\frac{S M(1+r)}{(1+r)^{2}}+\frac{S M(1+r)^{2}}{(1+r)^{3}}+\cdots+\frac{S M(1+r)^{t-1}}{(1+r)^{t}}
$$

While carrying out practical calculations related to the analysis of the economic efficiency of thermal protection measures of residential buildings, the numerator of the right-hand side of the equation (2) is replaced by an indicator characterizing the value of the average forecasted intermediate economy of funds for the entire economic life of the project, $\Delta S M$, rub.:

$$
\Delta S M=c_{t}\left(Q_{0}-Q_{1}\right)
$$

where $\quad \Delta S M$ - average intermediate economy of funds; ct - the average forecasted cost of a unit of thermal energy for the considered period of time, RUB/Gcal; Q0 Q1 - the thermal energy consumption for the heating of the building under consideration, respectively, before and after the thermal modernization, Gcal.

Further, when the capital investment index is transferred to the right-hand side of the equation, formula (2) takes the form of the known formula used to determine the net present value of the project $(N P V)$, which in this case should be called the net present economy of financial resources of the reconstruction project $(N D F)$ :

$$
N D F=\frac{\Delta S M}{1+r}+\frac{\Delta S M}{(1+r)^{2}}+\frac{\Delta S M}{(1+r)^{3}}+\cdots+\frac{\Delta S M}{(1+r)^{t}}-I C
$$

where NDF - net present economy of financial resources as a result of energy-saving measures on the reconstruction project of a residential building.

In the process of solving the tasks of economic efficiency of the thermal modernization method and the choice of building insulation systems, the forecasted values of the growth of prices for thermal energy and inflation growth rates are used. The forecast accuracy, namely the forecast of the discount rate $(r)$ and the average value of the intermediate economy of financial resources $(N D F)$, in turn, has a significant impact on the value of the payback period of capital investments in energy-saving measures. 
It is noted in the works that when carrying out a feasibility study of thermal protection measures, it is possible to forecast the cost of thermal energy and inflation rates at the beginning and at the end of the economic life of the project, and, further, with the subsequent determination of the average value of the forecasted indicators. The discount rate should be taken on the basis of the refinancing rate of the Central Bank, adjusted for certain types of risk $\mathrm{p}$ [4].

Two approaches are possible to determine the average forecasted cost of thermal energy. In the first case, an array of data on heat tariffs over the past few years is used, which is approximated by a linear dependence. The obtained straight line is prolonged for a given period of time and, consequently, the forecasted cost of thermal energy at the end of the period under consideration is determined. The average cost is determined as the arithmetic mean of the current and final values. In the second case, the forecasted cost of thermal energy is determined by the formula of compound interest:

$$
c_{T_{i}}=c_{T_{0}}(1+d)^{i}
$$

It should be noted that both of these approaches have one significant disadvantage - a distortion of the result obtained when trying to simplify the accounting of the variability of intermediate incomes. And with some calculating criteria, we get an overestimated payback period, while with others - an underestimated (Fig. 1). In certain periods, this distortion can be very small (for small accounting periods), and in other cases - large (for long accounting periods) $[5,6]$.

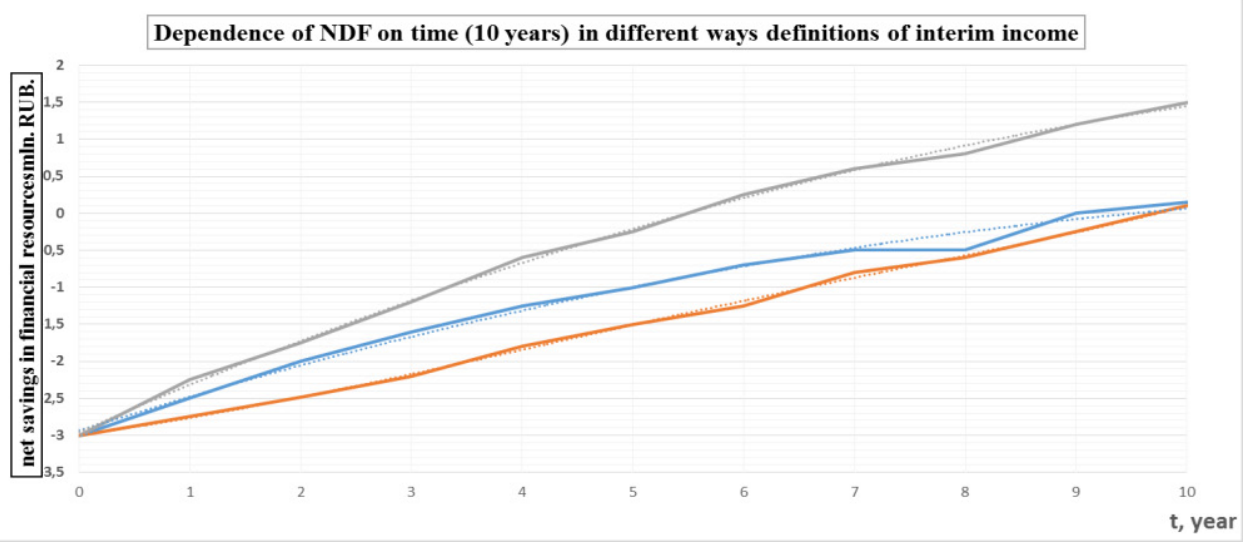

Fig. 1. Dependence of NDF on time for different ways of determining intermediate income - 10 years.

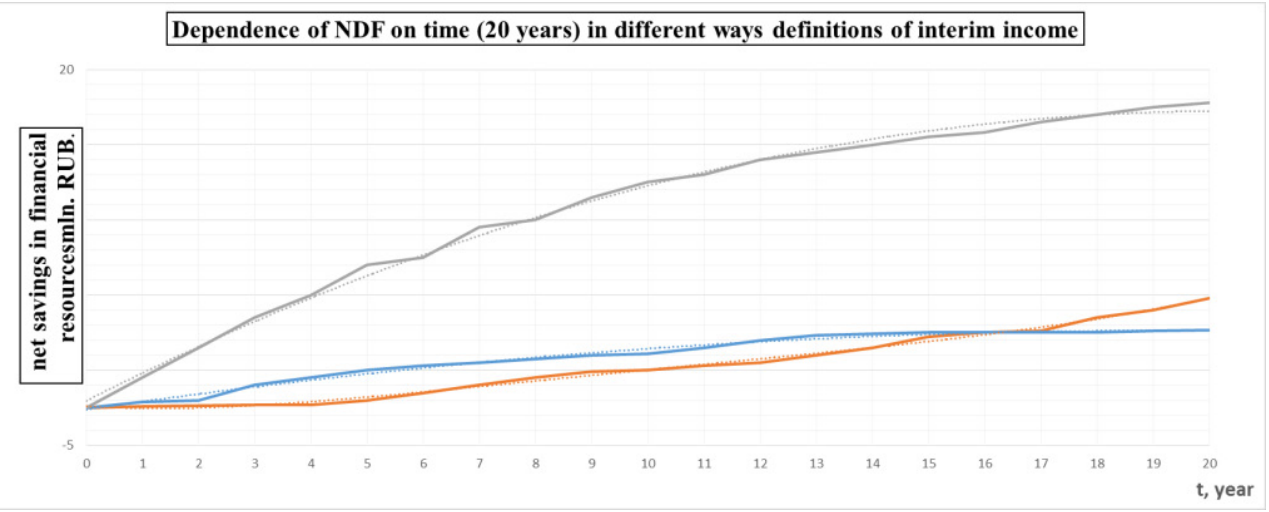

Fig. 2. Dependence of NDF on time for different ways of determining intermediate income 20 years. 
Therefore, a new approach to assessing the economic efficiency of thermal protection measures is proposed in this paper. Using formulas (2) and (3), instead of the value of $\Delta D$ we introduce the variable value of intermediate incomes $S M(1+d)$, determined on the basis of the forecasted dynamics of the change of tariffs for thermal energy $(d)$ :

$$
N D F=\left[\frac{S M}{1+r}+\frac{S M(1+d)}{(1+r)^{2}}+\frac{S M(1+d)^{2}}{(1+r)^{3}}+\cdots+\frac{S M(1+d)^{t-1}}{(1+r)^{t}}\right]-I C
$$

Further, one should simplify equation (4) by applying the geometric progression formula:

$$
N D F=\frac{c_{t_{0}}\left(Q_{0}-Q_{1}\right)}{r-d}\left[1-\left(\frac{1+d}{1+r}\right)^{t}\right]-I C
$$

Formula (7) is valid if $d \neq r$. In the case when $=r$, the equation becomes linear, the calculations are greatly simplified and the NDF exponent is derived from formula (2).

Let's consider how will change the payback period of costs during the process of determining the values of intermediate incomes, depending on the change in the forecasted value of the cost of thermal energy.

The factor of growth of tariffs for thermal energy can take the following values depending on the vector of development of the macroeconomic situation:

- tariffs are lower than the discount rate $d<r$;

- tariffs are equal to the discount rate $d=r$;

- tariffs are higher than the discount rate $d>r$.

The results of calculations, based on the analysis of tariff changes over the period of 20 years, are shown in Fig. 2.

The following options for the behavior of payback period are possible:

- option 1: if $d=r$, then the investment is repaid, but for a long period of time;

- option 2: if $d>r$, then the payback will occur earlier than in option 1;

- option 3: if $d<r$, then the payback will occur much later than in option 1; there is a possibility of the risk of a loss arising from an unfavorable change in the economic situation.

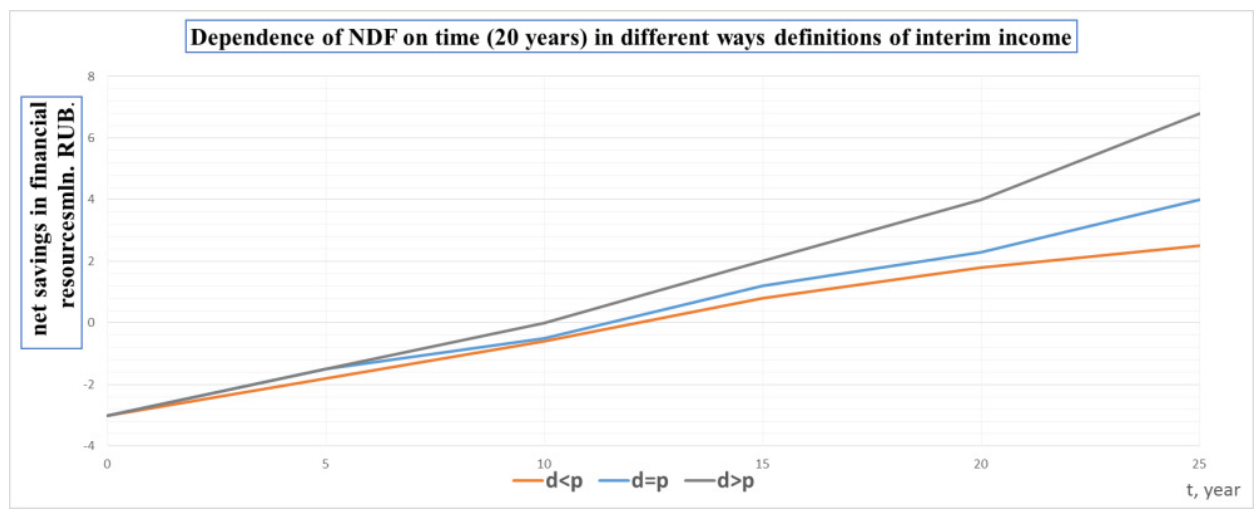

Fig. 3. Dependence of NDF on time for different options of the $d$ and $r$ ratio.

It should be noted that using the formula (6), it is necessary to observe the following condition - energy-saving measures for a residential building should be made at the current period of time. This is a disadvantage of this formula, and it is possible that the results will be different when performing deferred energy-saving measures for a residential building.

Therefore, we'll next consider the dynamics of the change in the value of NDF for thermal modernization measures implemented in the future, i.e. for the "deferred thermal 
modernization" option. To do this, we write formula (6) for the condition for carrying out energy-saving measures of a residential building not at the current moment of time, but in m years:

$$
N D F=\frac{c_{t_{0}}\left(Q_{0}-Q_{1}\right)}{r-d}\left[\left(\frac{1+d}{1+r}\right)^{m}-\left(\frac{1+d}{1+r}\right)^{m+t}\right]-I C
$$

Calculations made by formula (8) have shown that the behavior of the function $N D F=$ $f(t)$ for different options of the $\mathrm{d}$ and $\mathrm{p}$ ratio will be as follows (Fig. 3):

- option 1: in case the growth of tariffs corresponds to an increase in the discount rate, i.e $d=r$, the behavior of the function $N D F=f(t)$ remains unchanged, which stipulates constancy of the payback period regardless of the time of energy-saving measures;

- option 2: in case the growth of tariffs for thermal energy will outrun the growth of the discount rate, i.e. $d>r$, the payback period of costs will decrease year by year, which stipulates the investment attractiveness of energy-saving measures;

- option 3: in case the growth of tariffs for thermal energy will lag behind the discount rate $(d<r)$, the reverse situation will be observed - energy-saving measures will be unprofitable for the investor.

For a comprehensive assessment of the efficiency of measures for thermal modernization of residential buildings, it is necessary to take into account not only the interests of investors, but also of the owners of residential houses (apartments). Therefore, formula (8) has disadvantages - it does not take into account the additional costs associated with the costs of high energy consumption under the condition of deferred thermal modernization of a residential building, which is not relevant for outside investors, but it is important for the owners of apartments. Therefore, we will correct formula (8) to account for these additional costs (losses):

$$
N D F=\frac{c_{t_{0}}\left(Q_{0}-Q_{1}\right)}{r-d}\left[\left(\frac{1+d}{1+r}\right)^{m}-\left(\frac{1+d}{1+r}\right)^{m+t}\right]-I C-C_{\text {oper }}
$$

where $C_{\text {oper }}$ - operating costs before the energy-saving measures (associated with overestimated energy consumption)

In its turn, the indicator $\mathrm{C}_{\text {oper }}$ is determined by the following formula:

$$
C_{\text {oper }}=\frac{c_{t_{0}}\left(Q_{0}-Q_{1}\right)}{r-d}\left[1-\left(\frac{1+\mathrm{d}}{1+\mathrm{r}}\right)^{\mathrm{m}}\right]
$$

Then the NDF indicator, as a comprehensive assessment of the efficiency of energysaving measures for a residential building, can be presented in the following form:

$$
\begin{gathered}
N D F=\frac{c_{t_{0}}\left(Q_{0}-Q_{1}\right)}{r-d}\left[\left(\frac{1+d}{1+r}\right)^{m}-\left(\frac{1+d}{1+r}\right)^{m+t}\right]-I C-\frac{c_{t_{0}}\left(Q_{0}-Q_{1}\right)}{r-d}\left[1-\left(\frac{1+\mathrm{d}}{1+\mathrm{r}}\right)^{\mathrm{m}}\right]= \\
=\frac{c_{t_{0}}\left(Q_{0}-Q_{1}\right)}{r-d}\left[2\left(\frac{1+d}{1+r}\right)^{m}-\left(\frac{1+d}{1+r}\right)^{m+t}-1\right]-I C
\end{gathered}
$$

The formula (11) is valid for an economic situation when $d \neq r$.

Therefore, considering this condition, Fig. 4 shows the analysis of only two situations: $d<r$ and $d>r$. Based on the analysis of the behavior of these two graphs, we can say that in any case, with an increase in the time for beginning of implementation of measures for the thermal protection of a residential building, the payback period will grow, and this is reasonable. However, it should be recalled that a study of the payback period for the costs is carried out for deferred energy-saving measures. In this case, the payback period includes two components - the payback period for the measures themselves and the payback period for the costs of operation of apartments before thermal modernization, associated with increased energy consumption. 


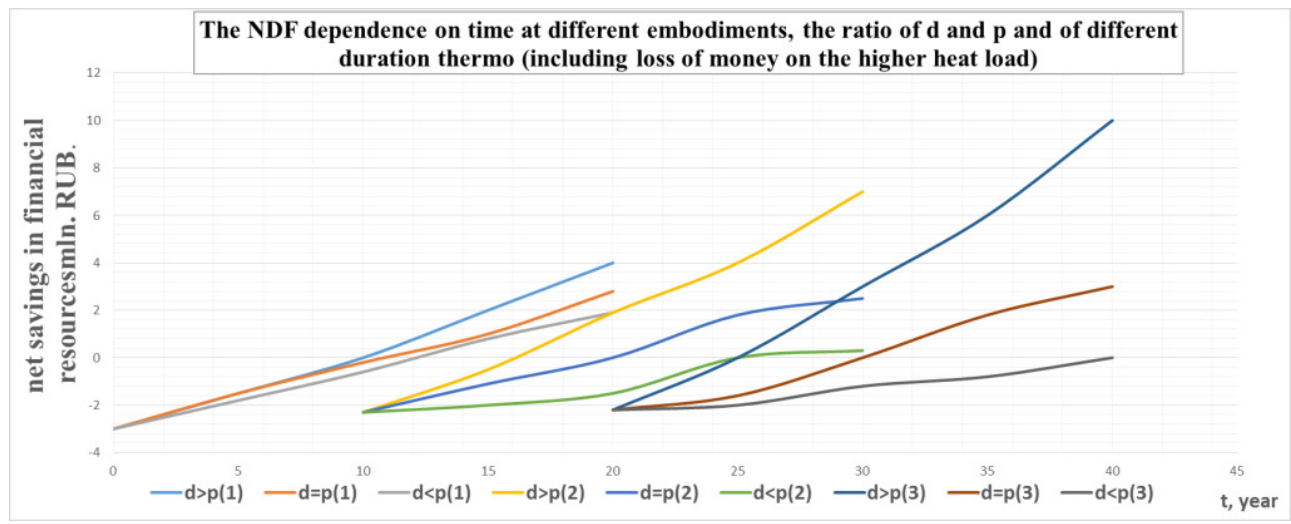

Fig. 4. Dependence on time for different options of the $\mathrm{d}$ and $\mathrm{r}$ ratio and different starting dates of energy-saving measures.

The results obtained by formula (11) are of interest not so much for investors as for owners of the apartments. With an increase of the starting date of energy-saving measures in the process of reconstruction of a residential building, the costs associated with the operation of apartments will only increase. The calculations show that an additional period of time will be required for payback of the operating costs associated with the deferral of measures, even after the investor's costs have been repaid.

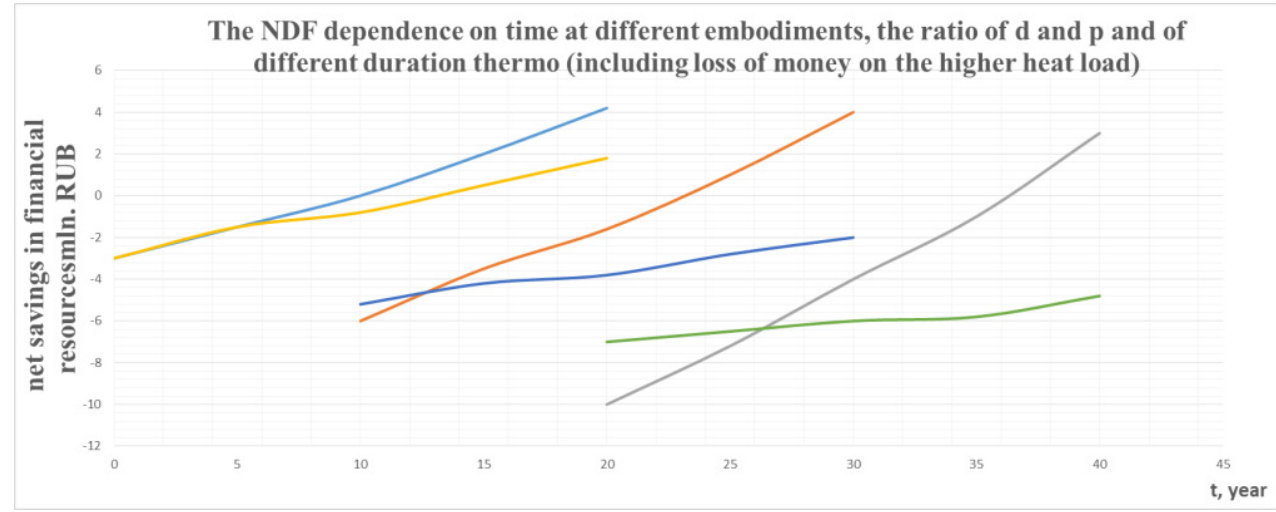

Fig. 5. Dependence on time for different options of the $d$ and $r$ ratio and different starting dates of energy-saving measures.

Based on the conducted study, it can be concluded that the establishment of a forecast indicator of the cost of thermal energy during the period of the reconstruction project is a complex and significant step in assessing the efficiency of the reconstruction project [7].

In addition, the simplification of calculation formulas by applying constant values of intermediate incomes determined on the basis of the average forecasted cost distorts the resulting efficiency criteria.

\section{Results}

When conducting a comparative assessment of the economic efficiency of energy-saving measures carried out during the reconstruction of a residential building, the following criteria can be applied:

1. Net present economy of financial resources 
Net present economy of financial resources, as a result of the energy-saving measures for the project of reconstruction of a residential house, is determined by the formula (rubles):

$$
\begin{gathered}
\mathrm{NDF}=\frac{\mathrm{ct}_{\mathrm{t}_{0}}\left(\mathrm{Q}_{0}-\mathrm{Q}_{1}\right)}{\mathrm{r}-\mathrm{d}}\left[1-\left(\frac{1+\mathrm{d}}{1+\mathrm{r}}\right)^{\mathrm{t}}\right]-\mathrm{IC}, \text { with } \mathrm{p} \neq \mathrm{d} \\
\mathrm{NDF}=\frac{\mathrm{c}_{\mathrm{t}_{0}}\left(\mathrm{Q}_{0}-\mathrm{Q}_{1}\right) \mathrm{t}}{\mathrm{r}-\mathrm{d}}-\mathrm{IC}, \text { with } \mathrm{p}=\mathrm{d}
\end{gathered}
$$

2. The payback period of capital investments

The payback period of capital investments, taking into account the discounting of income due to savings of consumption of energy resources, is determined by the formula (year):

$$
\begin{gathered}
\mathrm{T}_{\mathrm{d}}=\frac{\ln \left(1-\frac{\mathrm{IC}(\mathrm{r}-\mathrm{d})}{\mathrm{c}_{\mathrm{t}_{0}}\left(\mathrm{Q}_{0}-\mathrm{Q}_{1}\right.}\right)}{\ln \left(\frac{1+\mathrm{d}}{1+\mathrm{r}}\right)}, \text { with } \quad \mathrm{p} \neq \mathrm{d} \\
\mathrm{T}_{\mathrm{d}}=\frac{\mathrm{IC}(1+\mathrm{r})}{\mathrm{c}_{\mathrm{t}_{0}}\left(\mathrm{Q}_{0}-\mathrm{Q}_{1}\right)}, \quad \text { with } \quad \mathrm{p}=\mathrm{d}
\end{gathered}
$$

3. Profitability index of capital investments

The profitability index of capital investments under condition that all income is discounted is determined by the formula:

$$
\mathrm{IP}_{\mathrm{d}}=\frac{\mathrm{DF}}{\mathrm{IC}}, \text { where } \mathrm{DF}=\sum \mathrm{NDF}+\mathrm{IC}
$$

where DF - total discounted economy of financial resources.

\section{Discussions}

Fig. 1 shows that when performing calculations using formula (4), taking into account the constant intermediate incomes, the payback periods of costs turn out to be greatly underestimated. In addition, they will continue to decrease with an increase of the accounting period. This circumstance is caused by the accumulative essence of NDF. When the intermediate incomes are smoothed out, the process of accumulating the required amount will go faster. At the same time, if the value of the current tariff is taken as the average forecasted cost of thermal energy, one can get the opposite picture, when the payback period starts to increase with the growth of the time interval under consideration.

\section{Conclusions}

Besides, the use of formula (4) for different time intervals gives a discrepancy in payback periods. This discrepancy can be explained by the dependence of $\Delta S M$ on the payback period $T_{d}$, which is not known at the time of the calculations.

As a result, the solution of a task by using formula (4) becomes possible when applying the method of successive approximation. Formula (7) does not have these disadvantages and can be recommended for assessment of the investment attractiveness and economic efficiency of thermal modernization.

\section{References}


1. A. Mottaeva, IOP Conf. Series: Earth and Environmental Science 90, 012120 doi:10.1088/1755-1315/90/1/0121209 (2017)

2. A. Pimenova, S. Kuzmina, N. Morozova, A. Mottaeva, MATEC Web of Conferences 73, 07018 (2016) DOI: 10.1051/matecconf/20167307018

3. E. Nezhnikova, IOP Conf. Series: Earth and Environmental Science 90, 012161 (2017) doi:10.1088/1755-1315/90/1/012161

4. I.V. Ilin, A.B. Anisiforov, WSEAS Transactions on Business and Economics 11, 757764 (2014)

5. O. Kalinina, O. Valebnikova, Advances in Intelligent Systems and Computing 692, 1315-1322 (2018) doi: 10.1007/978-3-319-70987-1_139

6. A. Zaychenko, S. Gutman, O. Kalinina, Advances in Intelligent Systems and Computing 692, 453-462 (2018) doi: 10.1007/978-3-319-70987-1_48

7. A. Jones, G. Fallon, R. Golov, European Business Review 12(4), 187-197, https://doi.org/10.1108/09555340010336871 